\title{
Plasma atrial natriuretic factor concentrations in essential and renovascular hypertension
}

\author{
P LAROCHELLE, J R CUSSON, J GUTKOWSKA, E L SCHIFFRIN, P HAMET, \\ O KUCHEL, J GENEST, M CANTIN
}

\begin{abstract}
Plasma atrial natriuretic factor concentrations were measured in 44 patients with mild untreated essential hypertension and 48 normotensive controls. Mean venous plasma atrial natriuretic factor concentrations were 13.2 (SEM 1.5) and $13.0(1.3) \mathrm{ng} / \mathrm{l}$ in the hypertensive patients and controls, respectively. Plasma atrial natriuretic factor concentrations were significantly correlated with age in both groups.

Plasma atrial natriuretic factor concentrations were also measured during renal vein catheterisation in a group of 15 hypertensive patients; of these, eight had renovascular hypertension, and in all eight cases plasma atrial natriuretic factor concentrations were increased in the aorta and inferior vena cava.

It is concluded that mild essential hypertension is not associated with increased plasma atrial natriuretic factor concentrations, whereas an age related increase in concentrations occurs in hypertensive and normotensive people.
\end{abstract}

\section{Introduction}

Atrial natriuretic factor is a peptide hormone with potent diuretic, natriuretic, and vasoactive properties. ${ }^{2}$ Atrial natriuretic factor may be measured in plasma by radioimmunoassay, either directly or after extraction, ${ }^{3-5}$ and concentrations may be influenced by salt intake,${ }^{67}$ as well as by heart failure, ${ }^{48}$ cirrhosis, ${ }^{6}$ renal failure, ${ }^{9}$ atrial tachycardia, ${ }^{10}$ and pregnancy. ${ }^{11}$ Because atrial natriuretic factor

\footnotetext{
Clinical Research Institute of Montreal, Hôtel-Dieu de Montréal, and Département de Médecine, Pathologie et de Pharmacologie, Université de Montréal, Quebec, Canada

P LAROCHELLE, PHD, FRCP(C), associate professor of pharmacology J R CUSSON, MD, FRCP(C), research fellow, department of pharmacology J GUTKOWSKA, PHD, associate professor of medicine

E L SCHIFFRIN, PHD, FRCP(C), associate professor of medicine

P HAMET, PHD, FRCP(C), professor of medicine

O KUCHEL, DSC, FRCP(C), professor of medicine

J GENEST, MACP, FRSC, professor of medicine

M CANTIN, MD, PHD, professor of pathology

Correspondence and requests for reprints to: Dr Pierre Larochelle, Clinical Research Institute of Montreal, Montreal, Quebec, Canada H2W IR7.
}

increases sodium excretion and decreases blood pressure, certainly after exogenous administration, ${ }^{12-14}$ it may be postulated that atrial natriuretic factor plays a part in essential hypertension. Arendt $e t$ $a l,{ }^{15}$ Sugawara $e t a l,{ }^{16}$ and Sagnella $e t ~ a l^{17}$ have reported finding higher plasma atrial natriuretic factor concentrations in patients with essential hypertension than in normotensive subjects.

The aims of this study were to see whether plasma atrial natriuretic factor concentrations were increased in patients with essential and renovascular hypertension and also to examine the possible relations between atrial natriuretic factor and blood pressure, heart rate, and the renin-aldosterone state of the patient.

\section{Subjects and methods}

Ambulatory patients with essential hypertension were recruited between 1 November 1985 and 28 February 1986 provided that on more than two occasions their systolic blood pressure had been higher than $150 \mathrm{~mm} \mathrm{Hg}$ or their diastolic blood pressure higher than $90 \mathrm{~mm} \mathrm{Hg}$. All patients were evaluated and followed up at the hypertension clinic of the Montreal Clinical Research Institute. The diagnosis of essential hypertension had to be established before the study based on the absence of any clinical evidence of secondary hypertension; normal laboratory findings including results of a complete blood count, estimations of serum glucose, urea nitrogen, creatinine, and sodium and potassium concentrations, and urine analysis; and a hypertensive intravenous pyelogram. When clinically indicated (15 cases) a renogram and renal arteriogram were obtained. Blood pressure (standard mercury sphygmomanometer) and heart rate were measured after 10 minutes in the supine position, diastolic pressure being read at phase $\mathrm{V}$ of Korotkoff sounds. Blood was then drawn for the determination of plasma atrial natriuretic factor concentration, peripheral renin activity, and aldosterone value. Height (without shoes) and weight (light clothes) were measured. Patients with essential hypertension were included if they had not been treated with antihypertensive agents or if such treatment had been discontinued at least three weeks before the study. Patients were excluded if they had evidence of target organ damage such as ventricular hypertrophy, proteinuria of greater than $200 \mathrm{mg}$ a day, or a serum creatinine concentration greater than $150 \mathrm{mmol} / \mathrm{l}$.

Eight other patients were found to have renovascular hypertension in the course of their investigation. The diagnosis was established $(a)$ by finding stenosis of a renal artery $(80 \%) ;(b)$ by a decreased renal blood flow on the side of the stenosis, as seen in the renogram; and $(c)$ by a renal vein ratio of plasma renin activity greater than 1.5 on the side of the stenosis versus the contralateral side. In these patients plasma atrial natriuretic factor concentrations were determined during renal vein catheterisation. 
During the same period a group of healthy normotensive volunteers who had not taken any drugs were asked to serve as controls. Subjects were included if they had a normal physical examination and normal laboratory test results, including a complete blood count, biochemical profile (sequential multiple analysis 20), and urine analysis. Smoking or a familial history of hypertension was not a reason for exclusion. They were excluded, however, if their systolic blood pressure was greater than $145 \mathrm{~mm} \mathrm{Hg}$ or if their diastolic blood pressure was equal to or greater than $90 \mathrm{~mm} \mathrm{Hg}$. Controls followed the same protocol as the patients with essential hypertension with regard to blood pressure and heart rate measurements as well as to the determination of plasma atrial natriuretic factor concentrations, plasma renin activity, and aldosterone concentrations.

Analytical methods-Plasma atrial natriuretic factor concentrations were determined by radioimmunoassay according to the method of Gutkowska et al after extraction of plasma. ${ }^{3}$ Plasma renin activity ${ }^{18}$ and plasma aldosterone concentrations ${ }^{19}$ were determined by radioimmunoassay.

Statistical analysis-Results are expressed as means and the range, standard error of the mean (SEM), or $95 \%$ confidence interval. To determine the significance of differences between means analysis of covariance was used in order to account for age. The significance of a relation between two variables was assessed by Pearson's coefficient of correlation and by partial correlations in order to account for possible confounding factors. Statistical analyses were done using the statistical package for the social sciences. In the analysis of covariance hypertensive patients were compared with controls and women compared with men. $\chi^{2}$ Analysis was used to test the difference in male to female ratio between controls and patients. The $p$ value for significance was set at 0.05.

\section{Results}

\section{STUDY GROUPS}

The study groups comprised 44 patients with essential hypertension and 48 normotensive controls. Table I gives their clinical and laboratory details. Though there were proportionally more men in the hypertensive group, there was no significant interaction between the study group and sex for any variable listed. Mean age and height were similar in the two groups, whereas patients tended to be heavier. On the other hand, patients with essential hypertension had similar plasma renin activities and aldosterone concentrations to the normotensive controls. These results take into account possible differences in age; height and plasma renin activity decreased with age, whereas systolic and diastolic blood pressures increased. Finally, nine patients had received antihypertensive agents in the past (diuretics, three patients; $\beta$ blockers, three; others, three).

TABLE I-Clinical and laboratory details of subjects studied. Except where stated otherwise values are means (ranges in parentheses) [95\% confidence intervals in square brackets]

\begin{tabular}{lcc}
\hline & Controls & $\begin{array}{c}\text { Hypertensive } \\
\text { patients }\end{array}$ \\
\hline No of subjects (M/F) & $48(21 / 27)$ & $44\left(28 / 16^{\star \star}\right)$ \\
Age (years) & $45(22-92)$ & $47(24-77)$ \\
Height $(\mathrm{cm})$ & $166(143-188)$ & $168(145-188)$ \\
Weight $(\mathrm{kg})$ & $64 \cdot 7(37-100)$ & $74 \cdot 5(37-129)$ \\
Systolic blood pressure $(\mathrm{mm} \mathrm{Hg})$ & $122[117$ to 126$]$ & $158[152 \text { to } 164]^{\star \star \star}$ \\
Diastolic blood pressure $(\mathrm{mm}$ Hg) & $74[71$ to 76$]$ & $94[91 \text { to } 98]^{\star \star \star}$ \\
Heart rate (beats/min) & $72[69$ to 75$]$ & $81[76 \text { to } 86]^{\star \star \star}$ \\
Plasma renin activity $(\mathrm{ng} / \mathrm{ml} / \mathrm{h})$ & $1 \cdot 02[0 \cdot 76$ to $1 \cdot 28]$ & $1.00[0 \cdot 58$ to $1 \cdot 40]$ \\
Plasma aldosterone $(\mathrm{ng} / \mathrm{dl})$ & $17 \cdot 9[15 \cdot 4$ to $20 \cdot 3]$ & $15 \cdot 3[11 \cdot 4$ to $19 \cdot 2]$ \\
\hline
\end{tabular}

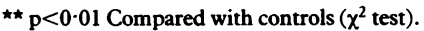

$\star \star \star p<0.001$ Compared with controls (after adjustment for age by covariance analysis).

\section{PLASMA ATRIAL NATRIURETIC FACTOR CONCENTRATIONS}

Figure 1 shows the individual and mean plasma atrial natriuretic factor concentrations in the normotensive and hypertensive subjects. Mean plasma atrial natriuretic factor concentrations were $13.2($ SEM 1.5$) \mathrm{ng} / \mathrm{l}$ in the hypertensive patients and $13.0(1.3) \mathrm{ng} / \mathrm{l}$ in the normotensive controls. This small difference was not significant $(95 \%$ confidence interval -1.9 to $1.8 \mathrm{ng} / \mathrm{l})$. Plasma atrial natriuretic factor concentrations tended to be higher in women controls (mean $16.0(1.9) \mathrm{ng} / \mathrm{l}$ ) than in normotensive men $(9 \cdot 1(1 \cdot 3) \mathrm{ng} / \mathrm{l})$.

Plasma atrial natriuretic factor concentrations were significantly correlated with age both in the hypertensive patients $(r=0.52 ; p<0.001)$ and in the normotensive controls $(r=0.35 ; p<0.02)$. The regression coefficients for this correlation were 0.38 in the hypertensive patients and 0.14 in the

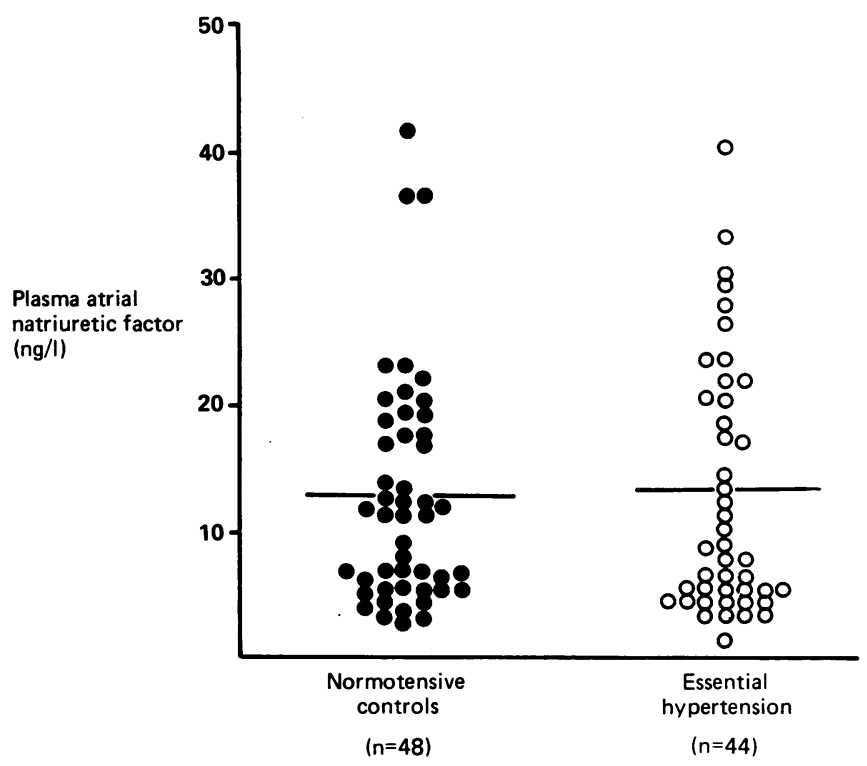

FIG 1-Individual atrial natriuretic factor concentrations in plasma of 48 normotensive controls and 44 patients with essential hypertension. Bars are means.

TABLE II-Plasma atrial natriuretic factor concentrations (ng/l) in patients with essential and renovascular hypertension during renal vein catheterisation. Values are means (SEM in parentheses)

\begin{tabular}{lccccc}
\hline & $\begin{array}{c}\text { No of } \\
\text { patients }\end{array}$ & Aorta & vena cava & $\begin{array}{c}\text { Inferior } \\
\text { vein }\end{array}$ & $\begin{array}{c}\text { Right renal } \\
\text { vein }\end{array}$ \\
\hline $\begin{array}{l}\text { Essential hypertension } \\
\text { Renovascular hypertension }\end{array}$ & 7 & $\begin{array}{c}25 \cdot 0(6 \cdot 0) \\
46 \cdot 5(10 \cdot 2)^{\star}\end{array}$ & $\begin{array}{l}16 \cdot 9 \cdot 1(3 \cdot 6) \\
29 \cdot 1(4 \cdot 7)^{\star}\end{array}$ & $\begin{array}{l}15 \cdot 0(3 \cdot 0) \\
18 \cdot 3(3 \cdot 1)\end{array}$ & $\begin{array}{l}13 \cdot 0(4 \cdot 0) \\
18 \cdot 4(3 \cdot 0)\end{array}$ \\
\hline
\end{tabular}

${ }^{\star} \mathrm{p}<0.05$ Compared with essential hypertension.

controls. These values were not significantly different and remained similar when allowing for sex. In the patients plasma atrial natriuretic factor concentration was not significantly correlated with systolic or diastolic blood pressure, nor with heart rate or plasma aldosterone concentration; plasma atrial natriuretic factor concentration, however, was negatively correlated with plasma renin activity $(\mathrm{r}=-0.50 ; \mathrm{p}<0.05)$, though this correlation disappeared after correction for age. In the normotensive controls plasma atrial natriuretic factor values were significantly correlated with systolic blood pressure $(r=0.35 ; \mathrm{p}<0.02)$ and negatively with both height $(r=$ $-0.53 ; \mathrm{p}<0.001)$ and weight $(r=-0.35 ; \mathrm{p}<0.02)$; these correlations were not improved by correction for age. Figure 2 shows the changes in plasma atrial natriuretic factor concentrations with age in the two groups.

\section{PLASMA ATRIAL NATRIURETIC FACTOR CONCENTRATIONS AND RENOVASCULAR HYPERTENSION}

Plasma atrial natriuretic factor concentrations were determined in the eight patients found to have renovascular hypertension (table II). In each case blood was obtained from the renal vein on both sides, from the inferior vena cava at infrarenal level, and from the aorta. Plasma atrial natriuretic factor concentrations in the inferior vena cava and aorta were significantly higher in these patients than in the seven subjects with essential hypertension who were submitted to the same investigation. Plasma atrial natriuretic factor concentrations in the renal veins also tended to be higher but not significantly so. The side of the renal artery stenosis did not seem to influence the plasma atrial natriuretic factor concentration in the renal vein, the mean concentration in the left vein being $18 \cdot 2(5 \cdot 1) \mathrm{ng} / \mathrm{l}$ in patients with right renal artery stenosis and $18.5(0.6) \mathrm{ng} / \mathrm{l}$ in patients with left sided stenosis. Concentrations in the right renal vein were $19.9(3.3) \mathrm{ng} / \mathrm{l}$ in patients with left renal artery stenosis and $17.5(4.5) \mathrm{ng} / \mathrm{l}$ in patients with stenosis on the right. The mean age of the eight patients with renovascular hypertension was 58 (3) years and of the seven patients with essential hypertension 51 (6) years. Mean blood pressure was $157(6) / 96(3) \mathrm{mm} \mathrm{Hg}$ in the patients with renovascular hypertension and $164(5) / 98(8) \mathrm{mm} \mathrm{Hg}$ in the seven subjects with essential hypertension. 


\section{Discussion}

Atrial natriuretic factor has potent diuretic, natriuretic, and vasodilatory activities when injected or infused into animals and man. ${ }^{612} 1320-23$ There is growing evidence that atrial natriuretic factor may have a role in volume homoeostasis through actions on receptors in the kidneys, ${ }^{23}$ adrenals, or vessel walls. ${ }^{2426}$ There is, however, no published evidence that small changes in atrial natriuretic factor concentration, as reported after alteration of sodium intake or position, influence volume homoeostasis or blood pressure control.

Sagnella et al reported an increase in the plasma concentration of atrial natriuretic factor in a group of 28 patients with essential hypertension (mean blood pressure 164 (3)/103 (2) mm Hg). ${ }^{17}$ We did not find such an increase in our series of 44 patients with essential hypertension, though their blood pressure was signifi- ventricular ejection fraction. ${ }^{33}$ The level of systolic pressure by itself is probably not an independent factor in most cases unless the pressure has been raised for very long periods, causing an increased pressure in both atria or left ventricular hypertrophy. After correction for age we could not show a correlation between systolic pressure and atrial natriuretic factor values. The combination of increasing age, systolic pressure with changes in pressure-volume relation may be determinant factors in the release of atrial natriuretic factor in a subject who otherwise has no evidence of cardiac or renal failure.

The increased plasma concentrations of atrial natriuretic factor in the patients with renovascular hypertension may also have been the result of a combination of factors such as raised blood pressure and age, but probably were mainly due to secondary hyperaldosteronism associated with the renal artery stenosis. This hyperaldosteronism would cause sodium retention and then

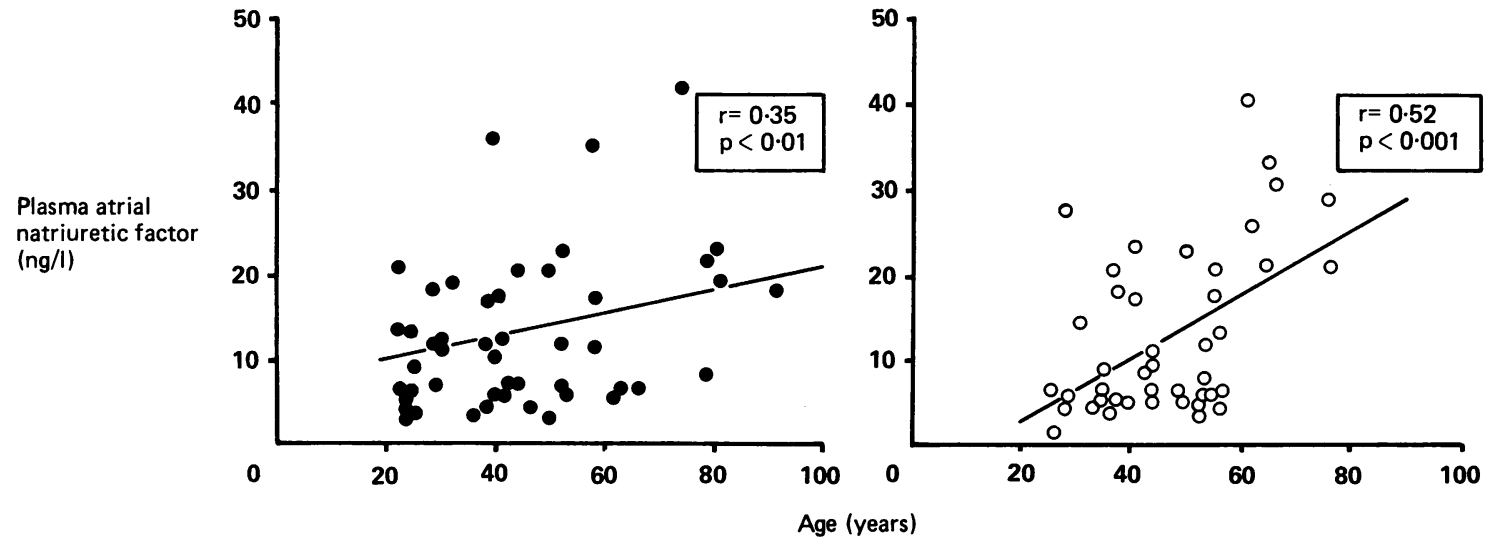

FIG 2-Age related increase in plasma atrial natriuretic factor concentrations in 48 normotensive controls (left) and 44 patients with essential hypertension (right).

cantly higher than that in the control group of 48 normotensive volunteers. The difference between the two results is difficult to explain: our study was larger, in both numbers of controls and numbers of hypertensive patients, but the patients reported on by Sagnella et al had higher blood pressures; both studies excluded patients with end organ damage. Though the studies differed in the posture of the subjects at sampling, ${ }^{17}$ this should not affect the comparison between hypertensive patients and normotensive controls. The duration of the hypertension was not known in either study and may have been a factor. Most patients in both studies had never been given antihypertensive drugs. Diet may also have been a factor if our patients with essential hypertension were adhering strictly to a low sodium diet. Urinary collections were not obtained; nevertheless, plasma renin activity and aldosterone values were identical in both groups.

In our study plasma atrial natriuretic factor concentrations in hypertensive patients correlated significantly with age and negatively with plasma renin activity; this second correlation, however, may have been accounted for by age. Whether the increase in atrial natriuretic factor concentration with aging contributes to the gradual decline of plasma renin activity with aging needs further investigation, as the cause of this reduction has not been clarified. ${ }^{28}$ Atrial natriuretic factor has been shown experimentally to be an inhibitor of renin secretion. ${ }^{29}$ In our patients with renovascular hypertension, however, plasma atrial natriuretic factor concentrations were comparatively high despite raised plasma renin activity.

Factors such as blood volume, ${ }^{30}$ dietary sodium, ${ }^{31}$ posture, ${ }^{5}$ and exercise $^{32}$ are known to be implicated in the release of atrial natriuretic factor. The gradual increase of the plasma concentration of atrial natriuretic factor with age in normal volunteers and patients with essential hypertension may be explained by a combination of many factors but, more specifically, by a reduced metabolic clearance, an increased systolic pressure, and a reduction in the increase plasma volume enough to raise the plasma atrial natriuretic factor concentration in the presence of hypertension. The blood pressure by itself may not be the main factor, as the patients with essential hypertension at a similar age and blood pressure had plasma concentrations of atrial natriuretic factor which were $50 \%$ lower.

The relation between the plasma concentration of atrial natriuretic factor and the blood pressure is not clear. It has been reported that patients with essential hypertension have an increased central venous pressure ${ }^{34}$ as well as raised pulmonary systolic and diastolic pressures. ${ }^{35}$ Hence our results are compatible with the possibility of a reduced responsiveness in the release of atrial natriuretic factor in patients with essential hypertension, as they have normal plasma concentrations of atrial natriuretic factor despite increased blood pressure.

We acknowledge Ms Lucette Gauthier, Mireille Kirouac, Colette Vanier, Marie-Ange Boutin, France Boulianne, Martine Bouchard, and Louise Falstrault for their help during the study and Ms Isabelle Blain for typing the manuscript. We also acknowledge Mr François Bellavance, of the department of mathematics and statistics of the Université de Montréal, for advice. This work was supported by grant MA 9304 from the Medical Council of Canada. JRC is supported by a fellowship from the Canadian Heart Foundation.

\section{References}

1 DeBold AJ, Borenstein HB, Veress AT, Sonnenberg HB. A rapid and potent natriuretic response to intravenous injection of atrial myocardial extract. Life Sci 1981;28:89-94.

2 Garcia R, Thibault G, Cantin M, Genest J. Effect of a purified atrial natriuretic factor on rat and rabbit vascular strips and vascular beds. Am f Physiol 1984;247:R34-9.

3 Gutkowska J, Bourassa M, Roy D, et al. Immunoreactive atrial natriuretic factor (IR-ANF) in human plasma. Biochem Biophys Res Commun 1985;128:1350-7.

4 Tikkanen I, Fyhrquist F, Metsarinne K, Leidenius R. Plasma atrial natriuretic peptide in cardiac disease and during infusion in healthy volunteers. Lancet $1985 ; \mathrm{ii}: 66-9$. 
5 Larose P, Meloche S, Du Souich P, De Léan A, Ong H. Radio-immunoassay of atrial natriuretic factor: human plasma levels. Biochem Biophys Res Commun 1985;130:553-8.

6 Shenker Y, Sider RS, Ostafin EA, Grekin RJ. Plasma levels of immunoreactive atrial natriuretic factor in healthy subjects and in patients with edema. $f$ Clin Invest 1985;76:1684-7.

7 Yamagi T, Ishiboshi $M$, Takaku F. Atrial natriuretic factor in human blood. $\mathcal{f}$ Clin Invest 1985;76:1705-9.

8 Ogawa $\mathrm{K}$, Ito $\mathrm{T}$, Hoshimoto $\mathrm{H}$, et al. Plasma atrial natriuretic factor in congestive heart failure. Lancet 1986; i:106.

9 Rascher W, Tulassay T, Lang RE. Atrial natriuretic peptide in plasma of volume-overloaded children with chronic renal failure. Lancet 1985;i:303-5.

10 Schiffrin EL, Gutkowska J, Kuchel O, Cantin M, Genest J. Plasma concentration of atrial natriuretic factor in patient with paroxysmal atrial tachycardia. N Engl f Med 1985;312:1196.

11 Cusson JR, Gutkowska J, Rey E, Michon N, Boucher M, Larochelle P. Plasma concentration of atrial natriuretic factor in normal pregnancy. $N$ Engl f Med 1985;313:1231.

12 Richards AM, Nicholls MG, Ikran H, Webster MWI, Yandle TG, Espiner EA. Renal haemodynamics and hormonal effects of human alpha atrial natriuretic peptide in healthy volunteers. Lancet 1985; ; 545 -9.

13 Richards AM, Nicholls MG, Espiner EA, et al. Effect of alpha human atrial natriuretic peptide in essential hypertension. Hypertension 1985;7:812-7.

14 Bussien JP, Biollaz J, Waeber B, et al. Dose dependent effect of atrial natriuretic peptides on blood pressure, heart rate and skin blood flow of normal volunteers. I Cardiovasc Pharmacol 1986;8:216-20.

15 Arendt RM, Stangl E, Zahringer J, Liebesch DC, Hertz A. Demonstration and characterization of human atrial natriuretic factor in human plasma. FEBS Lett 1985;189:57-61.

16 Sugawara A, Nakao K, Sakamoto $M$, et al. Plasma concentration of atrial natriuretic polypeptide in essential hypertension. Lancet 1985; 1 i: 1426-7.

17 Sagnella GA, Markanda ND, Shose AC, MacGregor GA. Raised circulating levels of atrial natriuretic peptides in essential hypertension. Lancet 1985;i:179-81.

18 Gutkowska J, Boucher R, Genest J. Dosage radioimmunologique de l'activité rénine plasmatique. Union Med Can 1977; 106:446-50.

19 Underwood B, Williams GH. The simultaneous measurement of aldosterone, cortisol and cortircsterone in human peripheral plasma by displacement analysis. $\mathrm{f} \mathrm{Lab} \mathrm{Clin} \mathrm{Med}$ 1972;79:848-62.

20 Garcia R, Thibault G, Gutkowska J, et al. Chronic infusion of low doses of atrial natriuretic factor (ANF Arg 101-Tyr 126) reduces blood pressure in conscious SHR without apparent changes in (ANF Arg 101-Tyr 126) reduces blood pressure in conscious

21 Garcia R, Thibault G, Gutkowska J, Hamet P, Cantin M, Genest J. Effect of chronic infusion of synthetic atrial natriuretic factor (ANF 8-33) in conscious two-kidney, one clip hypertensive rats. Proc Soc Exp Biol Med 1985;178:155-9.

22 Garcia R, Gutkowska J, Genest J, Cantin M, Thibault G. Reduction of blood pressure and $\underline{\underline{W}}$ increased diuresis and natriuresis during chronic infusion of atrial natriuretic factor (ANF Arg 101-Tyr 126) in conscious one kidney, one clip hypertensive rats. Proc Soc Exp Biol Med 1985;179:539-45.

23 De Léan A, Vinay P, Cantin M. Distribution of atrial natriuretic factor receptors in dog kidney 2 fraction. FEBS Lett 1985;193:239-42.

24 Chartier L, Schiffrin EL, Thibault G, Garcia R. Atrial natriuretic factor inhibits the stimulation of $\widehat{\widehat{\Omega}}$ aldosterone secretion by angiotensin II, ACTH and potassium in vitro and angiotensin II-induced steroidogenesis in vivo. Endocrinology 1984;115:2026-8. 25 Schiffrin EL, Chartier L, Thibault G, St-Louis J, Cantin M, Genest J. Vascular and adrenal $\underset{\mathbb{D}}{\mathrm{D}}$
receptors for atrial natriuretic factor in the rat. Circ Res 1985;56:801-7.

26 Hamet P, Tremblay J, Pang SC, et al. Effect of native and synthetic atrial natriuretic factor on TI cyclic GMP. Biochem Biophys Res Commun 1984;123:515-27.

27 Hollister AS, Tanaka I, Iamada T, et al. Sodium loading and posture modulates human atrial $\cdots$

28 Padfield PL, Beiners DG, Brown JJ, et al. Is low renin hypertension a stage in the development of $\stackrel{\overrightarrow{\bar{F}}}{+}$ essential hypertension or a diagnostic entity? Lancet 1975;i:548-54.

29 Villarenal D, Freeman RH, Davis JO, Verburg KM, Van RC. Renal mechanisms for suppression of renin secretion by atrial natriuretic factor. Hypertension 1986;8(suppl II):28-35.

30 Anderson JV, Christofides ND, Bloom SR. Plasma release of atrial natriuretic peptide in response $\frac{\omega}{\sigma}$ to blood volume expansion. $\mathcal{f}$ Endocrinol 1986;109:9-13.

31 Shenker Y, Seder RS, Ostafin EA, Greken RJ. Plasma levels of immunoreactive atrial natriuretic factor in healthy subjects and in patients with edema. $\mathcal{f}$ Clin Invest 1985;76:1684-7.

32 Tanaka $\mathrm{H}$, Shindo $M$, Gutkowska J, et al. Effect of acute exercise on plasma immunoreactiveatrial natriuretic factor. $L$ ife Sci 1986;39:1685-93.

$33 \mathrm{Kouz}$ S, Bourassa MG, Laurier J, et al. Plasma concentration of immunoreactive atrial natriuretic factor (IR-ANF) in patients with coronary artery disease. fournal of the American College of $\overrightarrow{\vec{v}}$ Cardiology 1986;7(suppl A):2.

34 London GM, Safar ME, Safar AL, Simon ACH. Blood pressure in the "low-pressure system" and cardiac performance in essential hypertension. Fournal of Hypertension 1985;3:337-42.

35 Olivari MT, Fiorentini C, Polese A, Guazzi MD. Pulmonary hemodynamics and right ventricular function in hypertension. Circulation 1978;57:1185-6.

(Accepted 17 February 1987)

\title{
Influence of salt on glycaemic response to carbohydrate loading
}

\author{
R O B GANS, R J HEINE, A J M DONKER, E A VAN DER VEEN
}

\begin{abstract}
The effect of dietary salt on glycaemic responses to different test meals was investigated. Eight healthy male volunteers ate four test meals on consecutive mornings and in random order; the meals were $50 \mathrm{~g}$ carbohydrate taken as a $20 \%$ glucose solution or as boiled macaroni with and without supplementation with $6 \mathrm{~g}$ salt. In contrast with other reports, no significant differences in peak plasma glucose concentrations or areas under the plasma glucose curves could be established.
\end{abstract}

These findings do not support a beneficial effect of salt restriction on glycaemic control in diabetes.

\section{Introduction}

The glycaemic response to standard test meals of various foods varies considerably in both normal volunteers and diabetics. ${ }^{12}$ Thorburn et al recently reported that adding salt to two common starchy foods resulted in an increase of the postprandial plasma glucose and insulin responses. ${ }^{3}$ A possible effect of dietary salt on the digestion of starch or absorption of glucose was postulated. This observation was even more interesting in the light of the observed

Department of Medicine, Free University Hospital, 1117 De Boelelaan, 1081 HV Amsterdam, The Netherlands

R O B GANS, MD, physician

$R$ J HEINE, MD, physician

A J M DONKER, MD, physician

E A VAN DER VEEN, MD, physician

Correspondence to: Dr Gans. association between plasma insulin concentrations and blood pressure. Both Berglund $e t$ al and Lucas $e t$ al found higher insulin concentrations in obese hypertensive patients than in normotensive subjects with the same body mass index ${ }^{45}$ Also in non-diabetic normotensive subjects significant associations of systolic and diastolic blood pressure with insulin concentrations have been observed even after allowing for adiposity. ${ }^{6}$ The possible influence of salt on glucose and insulin responses might therefore be implicated in the effect of dietary salt restriction on blood pressure in essential hypertension.

We have studied the plasma glucose response to a moderate $\delta$ amount of salt added to two foods containing $50 \mathrm{~g}$ carbohydratenamely, a readily absorbed glucose solution and boiled macaroni.

\section{Subjects and methods}

Eight healthy normotensive volunteers with a normal body mass index took a test meal on four consecutive mornings after an overnight fast. Meals $\underset{\omega}{N}$ were allocated at random according to a Latin square model and comprised $\sigma$ $50 \mathrm{~g}$ carbohydrate as either $71 \mathrm{~g}$ macaroni boiled for 10 minutes (intrinsic salt 0 content $3.6 \mathrm{mg}$ ) or $250 \mathrm{ml} 20 \%$ glucose with and without the addition of $6 \mathrm{~g}$ sodium chloride. The salt supplement was the only additive allowed. Zero $\&$ time was taken as the time that eating started, and the meal had to be finished in 10 minutes.

Blood samples were drawn from an indwelling antecubital venous cannula

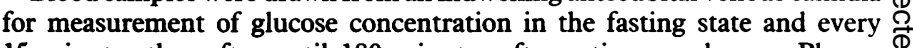
15 minutes thereafter until 180 minutes after eating was begun. Plasma $\triangle$ glucose concentrations were measured by a glucose oxidase method (Yellow Springs glucose analyser, Ohio, USA).

Results are expressed as medians and ranges. Incremental areas under the $\delta$ three hour glucose curves above fasting values were calculated. The Wilcoxon test for paired observations was used for assessing differences $\bar{Q}$ between salted and unsalted meals. The $95 \%$ confidence intervals for the 